http://jmscr.igmpublication.org/home/ ISSN (e)-2347-176x ISSN (p) 2455-0450

crossref DOI: https://dx.doi.org/10.18535/jmscr/v8i1.120

\title{
When Asymmetry is the rule only Dyke \& Davidoff Can Help An Interesting Case of Cerebral Hemiatrophy (Clinical Image)
}

\author{
Authors \\ Dr Suhas.M1, Dr Shivani Nayak ${ }^{2}$ \\ ${ }^{1}$ Assistant Professor in the Department of Neurology, Bangalore Medical College and Research Institute \\ ${ }^{2}$ Fellow in Phacorefractive Surgery, Lions Eye Superspecialty Hospital, Bangalore
}

\begin{abstract}
Here we present an interesting case of hemiatrophy of the brain resulting from any insult to the growing brain, which leads to corresponding phenotypic manifestations in the body.

Keywords: Hemiatrophy, Dyke-Davidoff-Mason syndrome.
\end{abstract}

\section{Case Details}

A 27 year old gentleman was referred from the ophthalmology department in view of dysmorphic facial features. On evaluation he was found to have a hemi facial atrophy, hemiparesis on the left side. There was no other significant past history. On routine imaging studies, he was found to have a grossly asymmetrical brain, with atrophy of all cerebral hemispheres proportionately on the right side along with increased thickness of the skull on the affected right side as shown.

Dyke-Davidoff-Masson syndrome is a clinical syndrome characterized by hemiparesis, facial hemiatrophy, seizures, speech impairment and occasionally mental retardation ${ }^{1}$.It is most often seen in the male gender. ${ }^{2}$ It was first described by the three clinicians in 1933 in a series of 9 patients describing in detail their clinical, radiological characteristics $^{3}$. The MRI features include the presence of cerebral hemiatrophy, calvarial thickening on the same side, pneumatisation of the sinuses on the same side $^{1}$.

The differential diagnosis ${ }^{4}$ in such cases to be considered are:

1. Dyke-Davidoff-Masson syndrome

2. Silver-Russel syndrome

3. Sturge-Webber syndrome

4. Rasmussen's encephalitis 


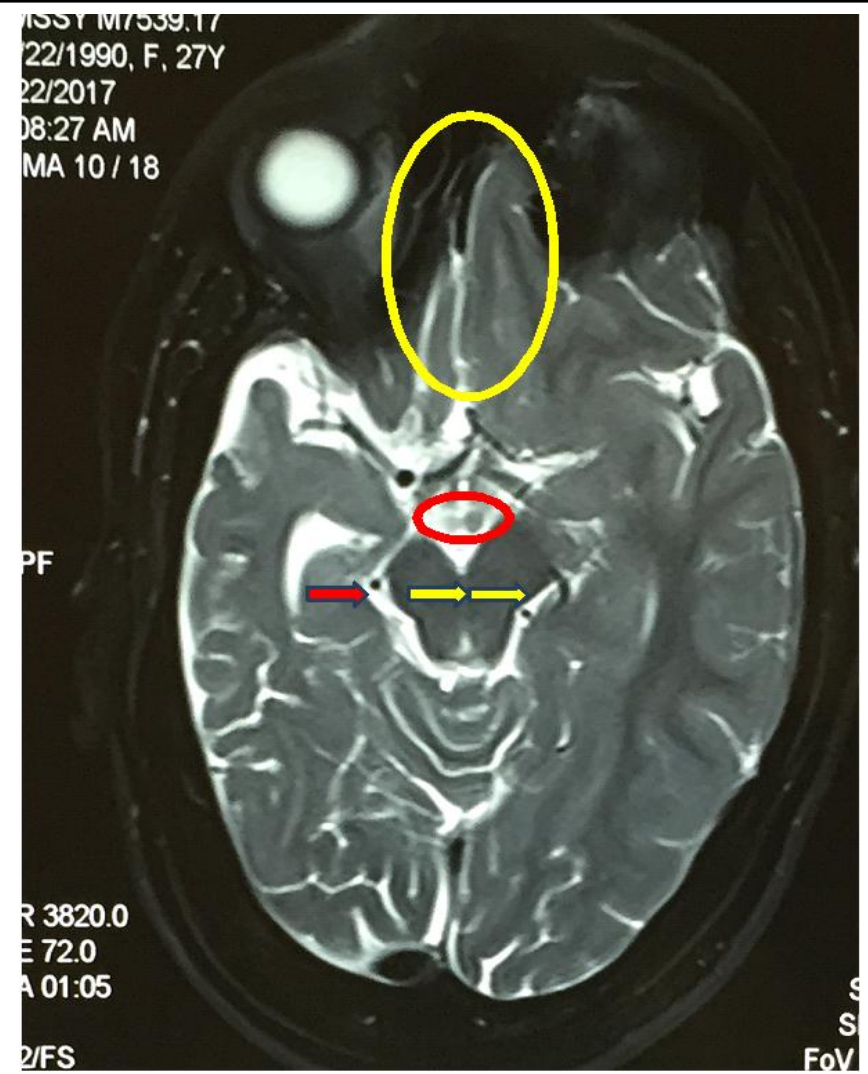

Figure-1: Shows an axial T2 weighted image which shows

1. Yellow Oval- Grossly asymmetrical gyrus $\underline{\text { rectus, }}$, right atrophied compared to left

2. Red Oval - Atrophied mammillary body on the left compared to the right

3. Yellow Arrow - Gross asymmetry in the sizes of the cerebral peduncles

4. Red Arrow- Dilated temporal horn of lateral ventricle on the right side as compared to the left side.

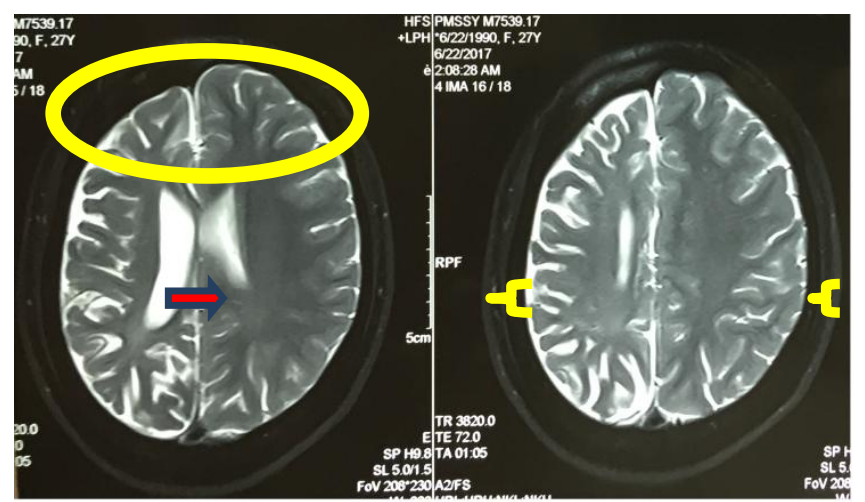

Figure-2: Shows an axial T2-Weighted MRI image which shows the characteristic asymmetry in the:
1. Yellow Oval- Sizes of the two hemispheres, along with the sulci-gyri patterns.

2. Red Arrow- Dilated Lateral ventricles on the affected right side.

3. Yellow Brackets- Thickness of the calvaria more on the right side. (although CT would have been more ideal modality to assess the skull thickness)

\section{References}

1. Dyke-Davidoff-Masson syndrome (DDMS) Pendse NA, Bapna P, Menghani V, Diwan A. Indian J Pediatr. 2004 Oct; 71(10):943.

2. Dyke CG, Davidoff LM, Masson CB. Cerebral hemiatrophy and homolateral hypertrophy of the skull and sinuses. Surg Gynecol Obstet. 1933;57:588-600

3. Left hemisphere and male sex dominance of cerebral hemiatrophy (Dyke-DavidoffMasson Syndrome), Unal O, Tombul T, Cirak B, Anlar O, Incesu L, Kayan M. Clin Imaging. 2004 May-Jun; 28(3):163-5.

4. Rao KC. Degenerative diseases and hydrocephalus. In: Lee $\mathrm{SH}$, Rao KC, Zimmerman RA, editors. Cranial MRI and CT. New York: McGraw-Hill; 1999. pp. 212-4. 